Tropical Journal of Pharmaceutical Research March 2021; 20 (3): 497-503

ISSN: $1596-5996$ (print); 1596-9827 (electronic)

(C) Pharmacotherapy Group, Faculty of Pharmacy, University of Benin, Benin City, 300001 Nigeria.

\title{
MiR-598-3p functions as a tumor suppressor in pediatric T- cell acute lymphoblastic leukemia
}

\author{
Zhang Qiang ${ }^{1}$, Jinhua Feng ${ }^{1}$, Chunlian Wang ${ }^{2}$, Meizhu Zheng ${ }^{3}$, Zhuoyu Wen ${ }^{4 *}$ \\ ${ }^{1}$ Department of Pediatrics, Changchun University of Traditional Chinese Medicine Affiliated Hospital, Changchun, ${ }^{2}$ Department \\ of Pediatrics, Jilin College of Traditional Chinese Medicine, Changchun, Jilin Province, ${ }^{3}$ Department of Child Healthcare, Jilin \\ Women and Children Health Hospital, Changchun, Jilin Province, 130021, ${ }^{4}$ Department of Pediatrics, Northwest Women and \\ Children's Hospital, Xi'an, Shaanxi Province 710054, China
}

*For correspondence: Email: wenzhuoyu0813@163.com; Tel: +86-29-89122753

Sent for review: 10 November 2020

Revised accepted: 20 February 2021

\begin{abstract}
Purpose: To investigate the role of miR-598-3p in pediatric $T$-cell acute lymphoblastic leukemia ( $T$ $A L L)$.

Methods: The expression of miR-598-3p in mononuclear cells isolated from the peripheral blood samples of children with or without T-ALL was assessed using real-time quantitative reverse transcription-polymerase chain reaction (qRT-PCR). Cell viability or proliferation of $T$-ALL cell lines was evaluated using cell counting kit-8 assay or bromodeoxyuridine staining, respectively. The target gene of miR-598-3p was predicted and validated using luciferase reporter assay, while the underlying mechanism involved in miR-598-3p-mediated T-ALL was determined by western blot analysis.

Results: MiR-598-3p was reduced in the peripheral blood mononuclear cells of T-ALL patients. Ectopic miR-598-3p expression decreased T-ALL cell viability and suppressed proliferation, while miR-598-3p interference showed reversed effects. Additionally, the target gene of miR-598-3p, Dishevelled, EGL-10, and Pleckstrin domain-containing mTOR-interacting protein (DEPTOR), was down-regulated by miR598-3p in T-ALL. MiR-598-3p decreased phospho (p)-AKT protein expression, while AKT inhibition counteracted the suppressive effects of miR-598-3p silencing on T-ALL cell viability and proliferation. Conclusion: MiR-598-3p/DEPTOR is involved in the proliferation of T-ALL through AKT pathway, thus providing a potential novel application in pediatric $T$-ALL.
\end{abstract}

Keywords: MiR-598-3p, DEPTOR, Progression, AKT pathway, Pediatric T-ALL

\begin{abstract}
This is an Open Access article that uses a fund-ing model which does not charge readers or their institutions for access and distributed under the terms of the Creative Commons Attribution License (http://creativecommons.org/licenses/by/4.0) and the Budapest Open Access Initiative (http://www.budapestopenaccessinitiative.org/read), which permit unrestricted use, distribution, and reproduction in any medium, provided the original work is properly credited.

Tropical Journal of Pharmaceutical Research is indexed by Science Citation Index (SciSearch), Scopus, International Pharmaceutical Abstract, Chemical Abstracts, Embase, Index Copernicus, EBSCO, African Index Medicus, JournalSeek, Journal Citation Reports/Science Edition, Directory of Open Access Journals (DOAJ), African Journal Online, Bioline International, Open-J-Gate and Pharmacy Abstracts
\end{abstract}

\section{INTRODUCTION}

Acute lymphoblastic leukemia (ALL), the most common hematologic tumor in children, accounts for approximately $25 \%$ of pediatric cancers [1]. ALL is characterized by the abnormal malignant proliferation of cells involved in the hematopoietic system, resulting in the infiltration of various organs such as lymph nodes, liver, bone marrow, and spleen [1]. T-cell ALL (T-ALL) is an aggressive malignancy of thymocytes and contributes to approximately $15 \%$ of pediatric ALL cases [2]. Advances in therapies have improved the outcomes for T-ALL treatment, and the 5-year event-free survival of T-ALL patients is more than $80 \%$ [2]. However, the overall survival 
of relapsed T-ALL is less than $25 \%$ [2]. Therefore, further investigation of the pathogenesis of pediatric T-ALL might provide more effective therapeutic strategies for the disease.

MicroRNAs (miRNAs) function as posttranscriptional regulators of target gene expression within functionally linked pathways and participates in biological processes [3]. Deregulated miRNAs in pediatric ALL suggest important regulatory roles [4]. Dysregulated miRNAs are prognostic biomarkers in T-ALL [5] and act as either oncogenic miRNAs [6] or tumor suppressors [7] in pediatric T-ALL. MiR-598-3p, a promising diagnostic biomarker for breast cancer [8], showed anticancer features in glioblastoma cells [9]. However, the effect of miR-598-3p in pediatric $T-A L L$ remains elusive.

Dishevelled, EGL-10, and Pleckstrin domaincontaining mTOR-interacting protein (DEPTOR) functions as an endogenous MTOR inhibitor [10] and participates in vascular endothelial activation, glucose homeostasis, and tumor progression [11]. Over-expression of DEPTOR is associated with a poor prognosis in thyroid carcinoma [12] and promotes cell survival in esophageal squamous cell carcinoma [13]. Interference of DEPTOR suppresses multiple myeloma progression [14]. Recently, ectopic DEPTOR expression was shown to promote TALL cell growth [15]. However, the role of DEPTOR in miR-598-3p-mediated T-ALL has not been investigated until now.

In the present study, the miR-598-3p expression levels in the peripheral blood mononuclear cells of pediatric T-ALL patients were examined, and the role and mechanism of miR-598-3p in T-ALL were investigated.

\section{EXPERIMENTAL}

\section{Patient samples}

The study was approved by the Ethics Committee of Northwest Women and Children's Hospital (approval no. 20-066) and followed the guidelines of 1964 Helsinki Declaration and its later amendments for ethical research involving human subjects [16]. Thirty-seven pediatric TALL patients and 35 healthy children with written informed consent were recruited from Changchun University of Traditional Chinese Medicine Affiliated Hospital. Peripheral blood samples were collected from the children, and mononuclear cells were isolated by density gradient centrifugation using Lymphoprep (Nycomed Pharma, Oslo, Norway).

\section{Cell culture, treatment and transfection}

T-ALL cell lines (6T-CEM and JURKAT) were acquired from DSMZ (Braunschweig, Germany) and cultured in RPMI-1640 medium (Transgene, Beijing, China) containing $10 \%$ fetal bovine serum (Sigma-Aldrich, St. Louis, MO, USA). For PI3K inhibition, T-ALL cells were seeded and treated with $50 \mu \mathrm{M}$ LY294002 (Sigma-Aldrich) 24 $\mathrm{h}$ before cell transfection. T-ALL cells were transfected with miR-598-3p mimic, inhibitor and the corresponding negative controls (NC mimic, NC inhibitor) (GenePharma, Shanghai, China) using Lipofectamine 2000 (Invitrogen, Carlsbad, CA, USA) according to the manufacturer's instructions.

\section{Cell counting kit-8 assay}

T-ALL cells $\left(2 \times 10^{3}\right.$ cells/well $)$ were seeded and cultured for $48 \mathrm{~h}$ before the cell viability assay (KeyGEN, Nanjing, China). The cells were incubated with $20 \mu \mathrm{L}$ of cell counting kit-8 solution for $4 \mathrm{~h}$ before measuring the absorbance at $450 \mathrm{~nm}$ using the Epoch microplate Reader (BioTek, Winooski, VT, USA) according to manufacturer's instructions.

\section{Bromodeoxyuridine incorporation}

T-ALL cells were seeded and cultured for $48 \mathrm{~h}$ before the cell proliferation assay (Bromodeoxyuridine ELISA kit; Roche Diagnostics, Basel, Switzerland). The cells were incubated with $10 \mu \mathrm{L}$ of $10 \mathrm{mM}$ bromodeoxyuridine for $2 \mathrm{~h}$ before measuring the absorbance at $450 \mathrm{~nm}$ according to the manufacturer's instructions.

\section{Luciferase reporter assay}

Wild-type or mutant 3'UTR DEPTOR sequences were constructed into the pGL3-basic vector (Promega, Madison, WI, USA). JURKAT cells were cotransfected with pRL-TK, miR-598-3p mimic/inhibitor, or NC mimic/inhibitor, and DEPTOR-WT or DEPTOR-MUT. The luciferase activities were measured $24 \mathrm{~h}$ later using the Luciferase Assay System (Promega) according to the manufacturer's instructions.

\section{Real-time quantitative reverse transcription- polymerase chain reaction (qRT-PCR)}

Total RNA was extracted using TRIzol (TIANGEN, Beijing, China) and reverse transcribed into cDNA. qRT-PCR was performed using the FAST SYBR Green Master Mix (Solarbio, Beijing, China) and the ViiA 7 system 
(Applied Biosystems, Austin, TX, USA). The PCR conditions were as follows: $95^{\circ} \mathrm{C}$ for $10 \mathrm{~min}$, followed by 40 cycles of $95^{\circ} \mathrm{C}$ for $15 \mathrm{~s}$ and $60^{\circ} \mathrm{C}$ for $1 \mathrm{~min}$. The primers used are listed Table 1.

Table 1: Primers used in PCR study

\begin{tabular}{lll}
\hline Gene & Sense & Antisense \\
\hline $\boldsymbol{m i R}$-598- & 5'- & 5'- \\
$\mathbf{3} \boldsymbol{p}$ & AGCTACGTCA & GTGTCGTCGAG \\
& TCGTTGTCATC & TCGGCAATTC-3' \\
DEPTOR & - 3' $^{\prime}-$ & \\
& TTTGTGGTGC & 5'- \\
& GATTGCTTTGTG \\
& 3' & \\
GAPDH & 5'- & 5'- \\
& GAGTCAACGG & GACAAGCTTCC \\
& ATTTGGTCGT- & CGTTCTCAG-3' \\
& 3' & \\
& 5'- & 5'- \\
& CTCGCTTTCG & AACGCTTCACG \\
& GCAGCACA-3' & AATTTGCGT-3' \\
\hline
\end{tabular}

\section{Western blotting}

T-ALL cell lysates $(30 \mu \mathrm{g})$ in RIPA (radioimmunoprecipitation assay) buffer were subjected to $10 \%$ sodium dodecyl sulfatepolyacrylamide gel electrophoresis and then were electro-transferred onto polyvinylidene fluoride membranes (Bio-Rad, Hercules, CA, USA). After blocking in $5 \%$ non-fat milk, the membranes were incubated with primary antibodies: DEPTOR (1:2000; Abcam, Cambridge, UK), p-AKT and AKT (1:2500; Abcam) and $\beta$-actin (1:3000; Abcam). The membranes were incubated with horseradish peroxidase-conjugated secondary antibody (1:5000; Abcam) before incubation with Pierce ECL Western Blotting Substrate (Pierce Biotechnology, Waltham, MA, USA) according to the manufacturer's instructions.

\section{Statistical analysis}

The data were reported as means \pm standard deviation and were analyzed by analysis of variance followed by the post hoc test using
SPSS 17.0. $p<0.05$ was considered statistically significant.

\section{RESULTS}

\section{Expression of miR-598-3p in pediatric T-ALL}

A significant decrease in miR-598-3p was observed in samples from pediatric T-ALL compared with those from healthy children $(p<$ 0.01) (Figure 1), suggesting that miR-598-3p might be involved in T-ALL progression. Analysis of the clinical and immunophenotypic features between pediatric T-ALL patients and healthy children suggested that the hemoglobin level, white blood cell count, and platelet count showed significant differences (Table 2).

\section{A}

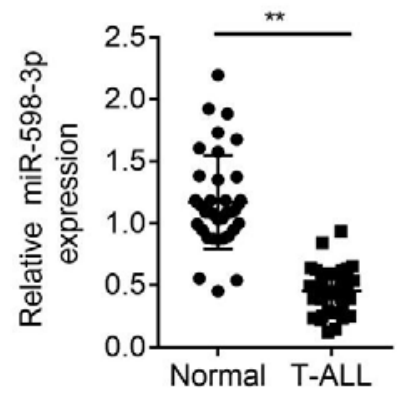

Figure 1: Expression of miR-598-3p in pediatric TALL. The miR-598-3p expression level was reduced in peripheral blood mononuclear cells isolated from pediatric T-ALL patients compared with that in healthy children. ${ }^{* *}$ T-ALL vs. Normal $p<0.01$

\section{MiR-598-3p suppresses T-ALL proliferation}

T-ALL cell lines (6T-CEM and JURKAT) were transfected with miR-598-3p mimic or inhibitor to assess the effect of miR-598-3p on T-ALL cell proliferation capability. Significant up-regulation of miR-598-3p was found in 6T-CEM and JURKAT cells transfected with miR-598-3p mimic compared with those transfected with NC mimic $(p<0.01)$ (Figure 2 A).

Table 2: Clinical and immunophenotypic features of T-ALL patients and normal controls

\begin{tabular}{lccc}
\hline Characteristic & T-ALL patient $(\mathbf{n = 3 7 )}$ & Normal control $(\mathbf{n}=\mathbf{3 5})$ & $\boldsymbol{P}$-value \\
\hline Sex (M/F) & $(21 / 16)$ & $(19 / 16)$ & 0.833 \\
Age (years) & $6.0(1-14)$ & $6.5(1-14)$ & 0.088 \\
Hemoglobin level & $9.58(4.21-17.5)$ & $151.02(102.11-198.63)$ & $<0.001^{* * *}$ \\
WBC count*10 & $150.20(4.41-236)$ & $17.78(3.1-36.89)$ & $<0.001^{* * *}$ \\
Platelet count*109 & $107.59(9.89-608)$ & $165.33(103.13-278.92)$ & $0.025^{*}$ \\
Thymic cell count $(\%)$ & $11 / 37(29.72)$ & $15 / 35(42.86)$ & 0.246 \\
Mature T-cell count $(\%)$ & $13 / 37(35.14)$ & $12 / 37(32.43)$ & 0.806 \\
Prethymic cell count $(\%)$ & $12 / 37(32.43)$ & $6 / 35(17.14)$ & 0.134 \\
\hline
\end{tabular}


The data from the cell counting kit-8 assay (Figure 2 B) and bromodeoxyuridine incorporation (Figure $2 \mathrm{C}$ ) revealed that forced expression of miR-598-3p decreased the cell viability and suppressed T-ALL proliferation, suggesting the anti-proliferative role of miR-598$3 p$ in T-ALL. However, miR-598-3p knockdown by transfection with miR-598-3p inhibitor (Figure 3 A) increased cell viability (Figure 3 B) and promoted cell proliferation (Figure $3 \mathrm{C}$ ) of T-ALL, confirming the suppressive role of miR-598-3p in T-ALL.
A

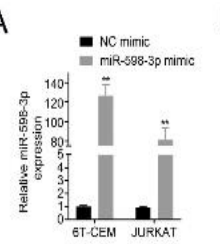

B

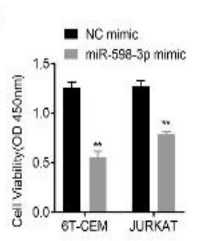

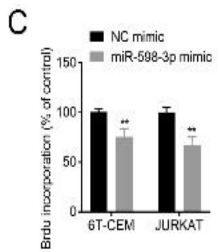

Figure 2: MiR-598-3p suppresses T-ALL proliferation. (A) Transfection of miR-598-3p mimic increased miR598-3p expression in 6T-CEM and JURKAT cells compared with NC mimic transfection. (B) MiR-598-3p mimic transfection decreased the cell viability of $6 \mathrm{~T}$ CEM and JURKAT cells compared with NC mimic transfection. (C) Transfection with miR-598-3p mimic decreased the cell proliferation of 6T-CEM and JURKAT cells compared with NC mimic transfection; ${ }^{* *} p<0.01, \mathrm{miR}-598-3 p$ mimic vs NC mimic
A

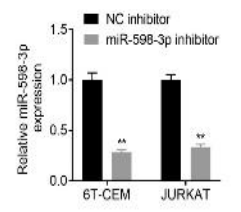

B

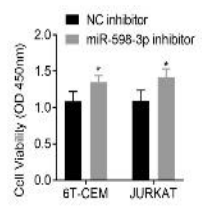

C

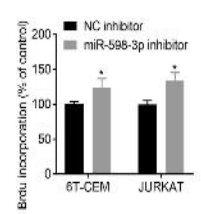

Figure 3: Knockdown of miR-598-3p promotes T-ALL proliferation. (A) Transfection of miR-598-3p inhibitor decreased miR-598-3p expression in 6T-CEM and JURKAT cells compared with NC inhibitor transfection. (B) Transfection with miR-598-3p inhibitor increased the cell viability of 6T-CEM and JURKAT cells compared with NC inhibitor transfection. (C) Transfection with miR-598-3p inhibitor increased the cell proliferation of 6T-CEM and JURKAT cells compared with NC inhibitor transfection. ${ }^{*} p<0.05$, miR-598-3p inhibitor vs NC inhibitor. ${ }^{* *} p<0.01$, miR598-3p inhibitor vs NC inhibitor

\section{DEPTOR is a target of miR-598-3p in T-ALL}

The TargetScan bioinformatics prediction algorithm (http://www.targetscan.org/vert_72/) predicted a potential binding site between miR598-3p and DEPTOR (Figure 4 A). The luciferase activity of the DEPTOR-WT luciferase reporter vector was decreased by miR-598-3p mimic and increased by miR-598-3p inhibitor (Figure 4 B). However, NC mimic/inhibitor transfection had no significant effect on the luciferase activity of DEPTOR-MUT (Figure $4 \mathrm{~B}$ ), suggesting that DEPTOR was a target of miR598-3p in T-ALL. In addition, the mRNA (Figure 4 C) and protein levels (Figure $4 \mathrm{D}$ ) of DEPTOR were decreased in JURKAT cells transfected with miR-598-3p mimic but increased with miR$598-3 p$ inhibitor, suggesting the functional role of miR-598-3p/DEPTOR in T-ALL. Furthermore, miR-598-3p decreased the protein expression of p-AKT in JURKAT cells, while miR-598-3p knockdown increased p-AKT expression (Figure $4 \mathrm{D})$, suggesting that the miR-598-3p/DEPTOR axis might regulate the AKT pathway in T-ALL.

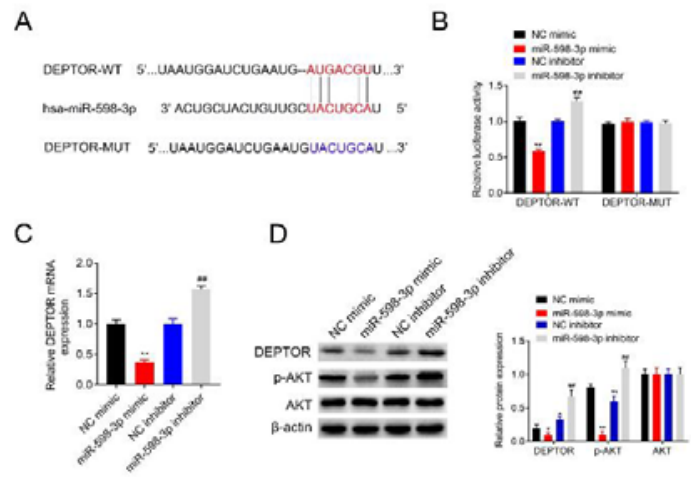

Figure 4: DEPTOR is a target of miR-598-3p in TALL. (A) Potential binding site, as well as the mutant site, between miR-598-3p and DEPTOR. (B) Transfection with miR-598-3p mimic decreased the luciferase activity of DEPTOR-WT, while transfection with miR-598-3p inhibitor increased the luciferase activity of DEPTOR-WT in JURKAT cells. (C)Transfection with miR-598-3p mimic decreased DEPTOR mRNA expression, while transfection with miR-598-3p inhibitor increased DEPTOR mRNA expression in JURKAT cells. (D) Transfection with miR-598-3p mimic decreased DEPTOR protein expression, while transfection with miR-598-3p inhibitor increased DEPTOR protein expression in JURKAT cells. ${ }^{*} p<0.05$, miR-598-3p mimic vs NC mimic. ${ }^{* *} p<0.01$, miR-598-3p mimic vs NC mimic. \#\# < 0.01, miR-598-3p inhibitor vs NC inhibitor

\section{Interference of AKT counteracts the suppressive effect of miR-598-3p on T-ALL cell proliferation}

To determine whether the AKT pathway was involved in miR-598-3p/DEPTOR-mediated TALL cell proliferation, 6T-CEM and JURKAT cells were pretreated with the PI3K inhibitor LY294002 and then transfected with miR-598-3p inhibitor. Pretreatment with LY294002 decreased T-ALL cell viability (Figure $5 \mathrm{~A}$ ) and suppressed T-ALL proliferation (Figure 5 B). Moreover, LY294002 treatment attenuated miR-598-3p inhibitorinduced increased cell viability (Figure $5 \mathrm{~A}$ ) and proliferation (Figure 5 B) of T-ALL. Thus, 
DEPTOR is a direct miR-598-3p target gene that promotes cell proliferation in T-ALL by inactivating the AKT pathway.
A

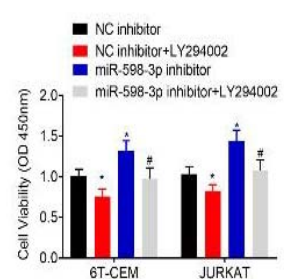

B

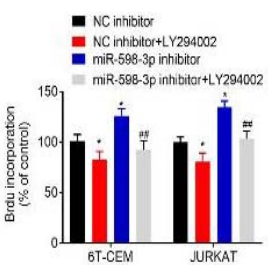

Figure 5: Interference of AKT counteracts the suppressive effect of miR-598-3p on T-ALL cell proliferation. (A) Pretreatment with the PI3K inhibitor LY294002 decreased the cell viabilities of 6T-CEM and JURKAT cells and attenuated miR-598-3p inhibitor-induced increased cell viability. (B) Pretreatment with the PI3K inhibitor LY294002 decreased the cell proliferation of 6T-CEM and JURKAT cells and attenuated miR-598-3p inhibitorinduced increased cell proliferation. ${ }^{*} p<0.05, \mathrm{NC}$ inhibitor + LY294002 vs NC inhibitor. \#p < 0.05, miR598-3p + LY294002 vs miR-598-3p inhibitor. \#p < 0.01, miR-598-3p + LY294002 vs miR-598-3p inhibitor

\section{DISCUSSION}

Specific miRNAs have been associated with risk factors involved in T-ALL and were regarded as prognostic biomarkers in T-ALL [5]. A previous study has shown that miR-598 is down-regulated in colorectal cancer tissues and is related to the poor prognosis of colorectal cancer [17]. MiR-598 predicts a poor prognosis in osteosarcoma [18]. The role and mechanism of miR-598-3p in T-ALL were then investigated in this study. We showed a significant decrease in miR-598-3p in the peripheral blood mononuclear cells of pediatric T-ALL patients compared with those of healthy children, suggesting possible diagnostic or prognostic roles in T-ALL. Moreover, forced miR598-3p expression decreased the cell viability and proliferation of T-ALL, while miR-598-3p interference reversed the effects. Because cell migration and invasion are important for T-ALL relapse [19], the effect of miR-598-3p on T-ALL metastasis warrants further investigation.

The luciferase activity data revealed that miR598-3p directly binds to DEPTOR in T-ALL. In addition, qRT-PCR and western blot analysis showed the inhibitory role of miR-598-3p on DEPTOR expression. Thus, miR-598-3p may repress T-ALL by down-regulating DEPTOR. A previous study showed the controversial function of DEPTOR in tumorigenesis. On the one hand, DEPTOR binds and inhibits hyperactivated mTOR in prostate cancer and suppresses tumorigenesis [20]. On the other hand, over- expressed DEPTOR in multiple myeloma promotes cell survival [10].

Aberrant PI3K/Akt/mTOR activation has been reported to indicate a poor prognosis of T-ALL, and inhibition of the PI3K/Akt/mTOR network is a promising innovative strategy for T-ALL [21]. DEPTOR inhibits p70S6K1 phosphorylation [22] and activates AKT [23] to promote T-ALL progression. In addition, DEPTOR inhibits mTORC1 and increases mTORC2 to phosphorylate S437 and T308 residues of AKT, thus activating THE AKT pathway to promote TALL progression [24]. The present study showed that miR-598-3p decreased p-AKT protein expression, while miR-598-3p knockdown increased $p-A K T$, suggesting that miR-598-3p might suppress T-ALL proliferation by inactivating the DEPTOR/AKT pathway. Moreover, consistent with a previous study reporting that PI3K/Akt pathway inhibition by LY294002 arrests cell growth and enhances the apoptosis of T-ALL [25], T-ALL cells pretreated with LY294002 in the present study also decreased cell viability and proliferation. LY294002 treatment counteracted the suppressive effect of miR-598-3p on T-ALL cell proliferation, further confirming that the AKT pathway was involved in miR-598-3p/DEPTORmediated T-ALL progression.

\section{CONCLUSION}

The findings of this study demonstrate that miR598-3p might function as a tumor suppressor in pediatric T-ALL, with miR-598-3p directly targeting DEPTOR to promote inactivation of the AKT pathway and suppression of T-ALL progression. These results may provide a means to develop a novel therapeutic miR-598-3p delivery approach for T-ALL.

\section{DECLARATIONS}

\section{Conflict of interest}

No conflict of interest is associated with this work.

\section{Availability of data and materials}

All the data generated or analyzed during this study are included in this published article.

\section{Contribution of authors}

We declare that this work was done by the authors named in this article and all liabilities pertaining to claims relating to the content of this 
article will be borne by the authors. Zhang Qiang and Jinhua Feng designed the study and supervised the data collection. Chunlian Wang analyzed and interpreted the data. Meizhu Zheng and Zhuoyu Wen prepared the manuscript for publication and reviewed the draft of the manuscript. All the authors have read and approved the manuscript.

\section{Open Access}

This is an Open Access article that uses a funding model which does not charge readers or their institutions for access and distributed under the terms of the Creative Commons Attribution License (http://creativecommons.org/licenses/by/ 4.0) and the Budapest Open Access Initiative (http://www.budapestopenaccessinitiative.org/rea d), which permit unrestricted use, distribution, and reproduction in any medium, provided the original work is properly credited.

\section{REFERENCES}

1. Pui C-H. Recent research advances in childhood acute lymphoblastic leukemia. J Formosan Med Assoc 2010; 109(11): 777-787.

2. Raetz EA, Teachey DT. T-cell acute lymphoblastic leukemia. Hematology 2016; 2016(1): 580-588.

3. Elbakkoush AA, Khaleel A, Liu C-T. MicroRNA and gene signature of severe cutaneous drug hypersensitivity reactions reveal the role of miR-483-5p/miR-28-5p in inflammation by targeting Granulysin gene. Tropical Journal of Pharmaceutical Research 2017; 16(4): 771779.

4. Schotte D, Chau JCK, Sylvester G, Liu G, Chen C, van der Velden VHJ, Broekhuis MJC, Peters TCJM, Pieters $R$, Boer MLd. Identification of new microRNA genes and aberrant microRNA profiles in childhood acute lymphoblastic leukemia. Leukemia 2009; 23(2): 313322.

5. Sabarimurugan $S$, Madurantakam Royam $M$, Kumarasamy C, Kodiveri Muthukaliannan G, Samiappan S, Jayaraj R. Prognostic miRNA classifiers in $t$ cell acute lymphoblastic leukemia: Study protocol for a systematic review and meta-analysis of observational clinical studies. Medicine 2019; 98(9): e14569-e14569.

6. Schotte $D$, Lange-Turenhout EAM, Stumpel DJPM, Stam RW, Buijs-Gladdines JGCAM, Meijerink JPP, Pieters R, Den Boer ML. Expression of miR-196b is not exclusively MLL-driven but is especially linked to activation of HOXA genes in pediatric acute lymphoblastic leukemia. Haematologica 2010; 95(10): 1675-1682.

7. Mets E, Van der Meulen J, Van Peer G, Boice $M$, Mestdagh P, Van de Walle I, Lammens T, Goossens S, De Moerloose B, Benoit $Y$ et al. MicroRNA-193b-3p acts as a tumor suppressor by targeting the MYB oncogene in T-cell acute lymphoblastic leukemia. Leukemia 2015; 29(4): 798-806.

8. Fu L, Li Z, Zhu J, Wang P, Fan G, Dai Y, Zheng Z, Liu Y. Serum expression levels of microRNA-382-3p, -598-3p, -1246 and -184 in breast cancer patients. Oncol Lett 2016; 12(1): 269-274.

9. Cesarini $V$, Silvestris $D A$, Tassinari $V$, Tomaselli $S$, Alon $S$, Eisenberg E, Locatelli F, Gallo A. ADAR2/miR-589-3p axis controls glioblastoma cell migration/invasion. Nucleic Acids Res 2018; 46(4): 2045-2059.

10. Peterson TR, Laplante M, Thoreen CC, Sancak $Y$, Kang SA, Kuehl WM, Gray NS, Sabatini DM. DEPTOR Is an mTOR Inhibitor Frequently Overexpressed in Multiple Myeloma Cells and Required for Their Survival. Cell 2009; 137(5): 873-886.

11. Bruneau S, Nakayama H, Woda CB, Flynn EA, Briscoe DM. DEPTOR regulates vascular endothelial cell activation and proinflammatory and angiogenic responses. Blood 2013; 122(10): 1833-1842.

12. Pei $L$, Xie $P$, Zhou $E$, Yang $Q$, Luo $Y$, Tang $Z$. Overexpression of DEP domain containing mTORinteracting protein correlates with poor prognosis in differentiated thyroid carcinoma. Mol Med Rep 2011; 4(5): 817-823.

13. Dong $X$, Wang $L$, Han $Z$, Zhou L, Shan L, Ding $Y, X u W$, $L i J, S U Y, C a i R$ et al. Different functions of DEPTOR in modulating sensitivity to chemotherapy for esophageal squamous cell carcinoma. Experimental Cell Research 2017; 353(1): 35-45.

14. Zhang HR, Chen JM, Zeng ZY, Que WZ. Knockdown of DEPTOR inhibits cell proliferation and increases chemosensitivity to melphalan in human multiple myeloma RPMI-8226 cells via inhibiting PIउK/AKT activity. J Int Med Res 2013; 41(3): 584-595.

15. Hu Y, Su H, Liu C, Wang Z, Huang L, Wang Q, Liu S, Chen $S$, Zhou J, Li $P$ et al. DEPTOR is a direct NOTCH1 target that promotes cell proliferation and survival in T-cell leukemia. Oncogene 2017; 36(8): 1038-1047.

16. Association WM. World Medical Association Declaration of Helsinki. Ethical principles for medical research involving human subjects. Bull WHO 2001; 79(4): 373.

17. Chen J, Zhang H, Chen Y, Qiao G, Jiang W, Ni P, Liu X, Ma L. miR-598 inhibits metastasis in colorectal cancer by suppressing JAG1/Notch2 pathway stimulating EMT. Exp Cell Res 2017; 352(1): 104-112.

18. Liu K, Sun X, Zhang Y, Liu L, Yuan Q. MiR-598: A tumor suppressor with biomarker significance in osteosarcoma. Life Sci 2017; 188(141-148.

19. Sharma ND, Nickl CC, Kang H, Ornatowski W, Winter SS, Loh ML, Hunger SP, Matlawska-Wasowska K. RUNX2 Regulates Cell Migration in T-Cell Lineage Acute Lymphoblastic Leukemia. Blood 2019; 134(Supplement_1): 3947-3947.

20. Chen X, Xiong X, Cui D, Yang F, Wei D, Li H, Shu J, Bi $Y$, Dai $X$, Gong $L$ et al. DEPTOR is an in vivo tumor suppressor that inhibits prostate tumorigenesis via the 
inactivation of mTORC1/2 signals. Oncogene 2020; 39(7): 1557-1571.

21. Bressanin D, Evangelisti C, Ricci F, Tabellini G, Chiarini F, Tazzari PL, Melchionda F, Buontempo F, Pagliaro $P$, Pession $A$ et al. Harnessing the PI3K/Akt/mTOR pathway in $T$-cell acute lymphoblastic leukemia: eliminating activity by targeting at different levels. Oncotarget 2012; 3(8): 811-823.

22. Hua C, Guo H, Bu J, Zhou M, Cheng H, He F, Wang J, Wang $X$, Zhang $Y$, Wang $Q$ et al. Rictor/mammalian target of rapamycin 2 regulates the development of Notch1 induced murine T-cell acute lymphoblastic leukemia via forkhead box O3. Exp Hematol 2014; 42(12): 1031-1040 e1031-1034.

23. Tamburini J, Chapuis $N$, Bardet V, Park S, Sujobert $P$, Willems $L$, Ifrah $N$, Dreyfus $F$, Mayeux $P$, Lacombe $C$ et al. Mammalian target of rapamycin (mTOR) inhibition activates phosphatidylinositol 3-kinase/Akt by up- regulating insulin-like growth factor-1 receptor signaling in acute myeloid leukemia: rationale for therapeutic inhibition of both pathways. Blood 2008; 111(1): 379382.

24. Liu H, Hu Y, Su H, Ye Q, Wang Z, Huang L, Wang Q, Chen S, Zhou J, Liu S et al. NOTCH1 Transcriptionally Activates Deptor and Promotes AKT Activation in Acute T-Cell Lymphoblastic Leukemia. Blood 2014; 124(21): 895-895.

25. Calzavara E, Chiaramonte $R$, Cesana $D$, Basile $A$, Sherbet GV, Comi P. Reciprocal regulation of Notch and PISK/Akt signalling in T-ALL cells in vitro. J Cell Biochem 2008; 103(5): 1405-1412.

26. Grabher C, von Boehmer H, Look AT. Notch 1 activation in the molecular pathogenesis of T-cell acute lymphoblastic leukaemia. Nat Rev Cancer 2006; 6(5): 347-359. 